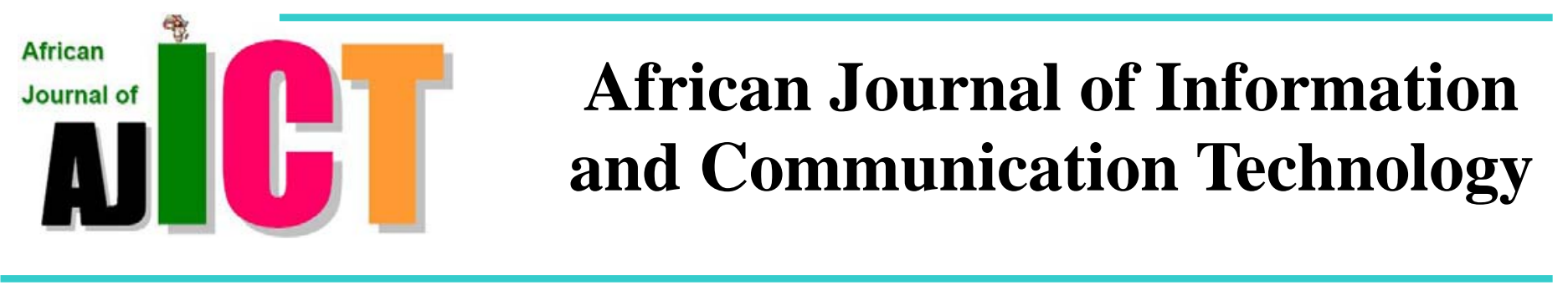

\title{
Copyright Transfer Form
}

The Author(s) of the manuscript entitled agree to execute copyright transfer forms. Copyright in this contribution is transferred to the African Journal of Information and Communication Technology. The manuscript contains the works of the authors and original material that has not been and will not be submitted or published by any other journal.

Full Name of Signatory

Affiliation and Position

Signed Date

Journal Home Page: http://epress.lib.uts.edu.au/journals/ajict/

\section{Editorial Office}

Faculty of Engineering, University of Technology, Sydney Building 1, 1 Broadway Street, Sydney 2007, Australia Email:agbinya@eng.uts.edu.au
Phone: +612 95142495

Fax: +612 95142435 